\title{
Products Suitable for Ecommerce: A Proposed Model for Click and Bricks Companies
}

\author{
Andrea Payaro, Anna Rita Papa \\ P\&P Consulting \& Service srl, Padua, Italy
}

\begin{abstract}
The Internet has become a means for socialising, shopping, and keeping informed. The true potential of the net is yet to be explored, given the many new electronic devices that can now access it. Online shopping is growing exponentially. Nevertheless, some products are easy to sell online, while others are still better to be sold at the local store. This paper aims to present a model that identifies the attributes that can improve the marketability of product by Internet: brand, "touch and feel", scarcity, price, and cost of returns. The model is being tested in 14 bricks and clicks retailers. Interviews with top management evaluate the validity of the attributes considered. All interviewed persons consider all of these attributes like a valid tool to select which products they can sell by Internet. The positive effects are the reduction of unsold goods, the increasing of visited pages in the web site, the reduction of costs due to returns, the increasing of income, and the rationalization of the offer. The information could help retailers adapt their strategies to fit customer's needs and attract and retain customers. From the marketing point of view, the knowledge from this study could help to create marketing strategies tailored to respond to online consumer's specific requirements and needs.
\end{abstract}

Keywords: e-commerce, attributes, click and brick

\section{Introduction}

The number of internet users has been steadily increasing all over the world, including developing countries. In Asia and Eastern Europe, internet access rates were considerably high during the last year. In addition, more than 70 percent of the population has access to internet from home in Western Europe, North America, and Australia, and by 2016 the number will be closer to 80 percent in these regions (Nielsen, 2014). E-commerce is big business and getting bigger every day. Retail sales worldwide - including both in-store and internet purchases - will reach $\$ 22,492$ trillion this year, according to new figures from eMarketer (2014). The global retail market will see steady growth over the next few years, and in 2018 , worldwide retail sales will increase $5.5 \%$ to reach $\$ 28,300$ trillion. The most popular e-commerce categories, not surprisingly, are non-consumable - durables and entertainment-related products. Nielsen (2014) reported that almost half of global respondents in an online survey intend to purchase clothing or make airline or hotel reservations using an online device in the next six months. Other categories growing in prominence for online shopping include e-books, event tickets, sporting goods, and toys (to name a few). The increase in online retail sales is influenced

Andrea Payaro, Ph.D. in business management, Chief Executive Officer of P\&P Consulting \& Service srl, Padua, Italy.

Anna Rita Papa, market researcher and analyst of P\&P Consulting \& Service srl, Padua, Italy.

Correspondence concerning this article should be addressed to Andrea Payaro, P\&P Consulting \& Service srl, Via Aldo Moro 37, I 35020 Legnaro PD, Italy. 
not only by pure players but also brick-and-mortar companies that have taken in the opportunities of e-commerce and are implementing multi-channel strategies (click and brick). It is clear that e-commerce has created opportunities for both small and large companies and a wide range of benefits for consumers as well. Although online stores have many advantages (convenience, easy access to product and service information, twenty-four seven, tools for product and price comparison), they also have disadvantages over brick-and-mortar stores. One of the most important disadvantages is the fact that consumers cannot touch, feel, taste, or smell the products; this prevents consumers from assessing product quality and increases risk perceptions.

\section{Problem Statement}

Researchers have been exploring online consumer behaviour for many years and two widely accepted views stand out in e-commerce literature: consumer-oriented and technology-oriented view (Cheung, Chan, \& Limayem, 2005). The consumer-oriented view places focus on consumer's salient beliefs about online shopping, whereas the technology-oriented view studies the impact of website design and usability on consumer's behaviour (Zhou, Dai, \& Zhang, 2007). The findings support both views and it is apparent in the literature that both views complement each other.

Numerous factors affect online consumer behaviour. There are mixed findings in literature and many factors that influence online consumer purchasing behaviour have yet to be explored, especially considering the dynamics of technology and consumer's needs and experience in online environment. Furthermore, most of the previous online shopping research is focused on one specific type of product such as books (Gefen, Karahanna, \& Straub, 2003; Lin, 2007), clothing (Ha \& Stoel, 2009; Tong, 2010), groceries (Hansen, Moller, \& Stubbe, 2004), and financial services (McKechnie, Winklhofer, \& Ennew, 2006).

Previous research has also investigated product characteristics and online behaviour using a conventional product classification scheme, exploring how search, experience, and credence goods vary in their impact on purchase intentions (Soopramanien, Fildes, \& Robertson, 2007). Few studies explore different product types and online purchasing intentions using a classification scheme that takes into account the specific features of Internet (Phau \& Meng Poon, 2000) and the findings show mixed results which call for further investigation.

From the preceding introduction, it is apparent that the fast technological progress is changing consumer shopping habits. Research on online consumer's behaviour is becoming more prominent in literature and prior studies have set the foundation into the factors that influence online consumers, however, it is still not clear what drives consumers to shop online. Moreover, e-commerce has become an important marketing and sales channel, complimenting traditional channels, thus, it is important for retailers to understand the determinants of online purchasing and what type of products are more suitable to be marketed online, as knowing, these factors will enable retailers to meet consumer's needs and for marketers to target consumers effectively.

The results from this study will provide valuable information for retailers about the relevant factors that drive consumers to shop online and the products. The information could help retailers adapt their strategies to fit customer's needs and attract and retain customers. From the marketing point of view, the knowledge from this study could help to create marketing strategies tailored to respond to online consumer's specific requirements and needs.

\section{The Proposed Model}

The model proposed here does not concern digitalised products, but rather those goods whose value is 
physical, and cannot be handled or managed as a sequence of bits. These products include items that are normally bought from supermarkets (home care, personal care, food, etc.), but also mechanical, electronic and electrical appliances, clothing, furniture and furnishings, and any other tangible item. These goods can be categorised according to a series of defining features that are an important part of the consumer's evaluation process. Indeed, it can be said that consumers purchase a product by evaluating all these aspects and at times attributing each of them a certain weight or importance. For product's categories that have a large number of sensory attributes (e.g., fruits and vegetables), the offline environment has more total information available to facilitate consumer choices. For product's categories which have a large number of non-sensory attributes (e.g., industrial products), the online environment will offer more total information than the offline environment.

This paper proposes a model with some attributes necessary to sell online (Figure 1). At moment, this study is not able to define the weight of each attribute, but this model can help the retailer to develop the right strategy of selling. The model proposed is being tested in 14 small and medium enterprises. One of the goals of this paper is to explore some "bricks and clicks" multi channel format (off line and online). The right product sold online affects the profits of competing retailers (Ofek, Katona, \& Sarvary, 2011, pp. 42-60).

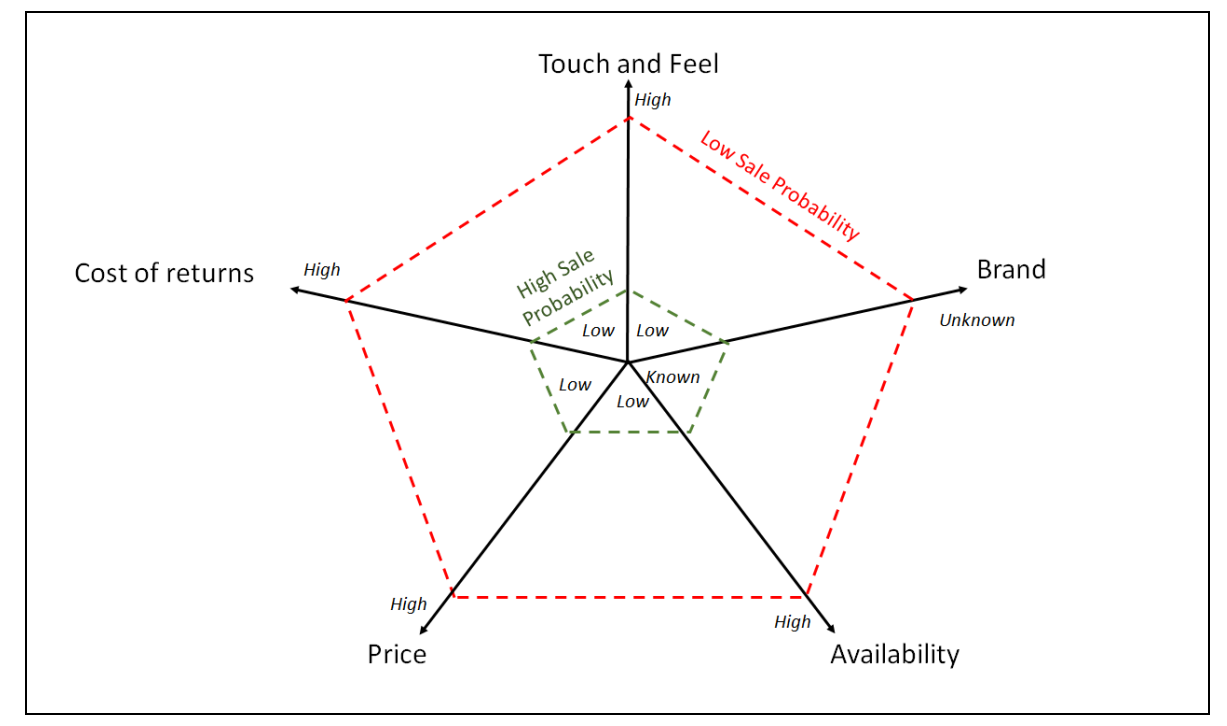

Figure 1. The proposed model with five attributes.

Product attributes tangible and intangible play a very important role in marketing from the perspective of the marketer and consumer and it has long been recognized as an opportunity to set the marketer's brand apart from competition (Kotler \& Armstrong, 2005). Consumers also value attributes since they are used as the basis for evaluating a product. Attributes also provide the benefits to consumers seek for purchasing a product and they are the elements or features that an object may or may not posses (Mowen, 1993).

Early researchers view product attributes as the physical properties of a product that were quantitatively and objectively measurable (Wu, Day, \& MacKay, 1988, pp. 88-113). However, in more recent years, it has expanded to include all evaluative criteria, including objective or physical properties i.e. price, brand name, or subjective criteria's such as quality, style, benefit, or value (Grapentine, 1995, pp. 18-27; Jamal \& Goode, 2001, pp. 140-155). Other authors have also looked into the intrinsic and extrinsic cues as evaluative criteria consumers employ when making a purchase decision (Forney, Pelton, Caton, \& Rabolt, 1999, pp. 57-62; Liefeld, Wall, \& Heslop, 2000). 
Product attributes evaluated by consumer have been found to be affected by a number of factors such as: situation, knowledge, motivation, and involvement (Engel, Blackwell, \& Miniard, 1993). The amount of cognitive and behavioural effort consumers put into their problem solving/decision making processes is highly dynamic and complex and for this reason, consumers need a great deal of information to form opinion and establish a set of criteria on which to judge specific brands. According to Aaker, Batra, and Myers (1992), an important attribute is one that offers an important benefit towards the satisfaction of consumer's needs. Aaker et al. (1992) added that because most product attributes provide consumer benefits, there is usually a one-to-one comparative between brands. Brands serve several valuable functions. For customers, brands can simplify choice, promise a particular quality level, reduce risk, and/or engender trust (Keller, 2002), consequently, brand is an attribute.

Literature presents the sensory attributes or "touch and feel" attributes and the same literature means those attributes that can be directly determined through senses, before consumers purchase the product. In this set of attributes, this paper identifies two subsets: digital sensory and non-digital sensory. By Internet, people can't reproduce some characteristics of a product. Smell, touch, and taste, at moment, are sensory attributes that they cannot be digitalized. By digital channel, it's possible to transfer shape, sound, and all attributes that can be conveyed reasonably well in words (e.g., nutritional information). Everyone can understand the characteristics of the goods by reading, like the origin (ingredients, raw materials), technical-functional features (speed, resolution, power consumption, etc.), and physical features (weight, size). Not surprisingly then, as a percentage of overall sales in each category, products for which consumers require more physical inspection to determine fit are sold less online (typically only 5\%-10\% of overall category sales) compared with products whose attributes and specifications can easily be communicated digitally (typically $45 \%-50 \%$ of overall category sales) (Mulpuru, 2008).

Many operators manufacture rarity or scarcity to increase the value of the assets they are selling. Scarcity is a dominant aspect of economic behaviour (Verhallen \& Robben, 1994). It signifies a loss of freedom and to negate this loss, people tend to desire products on which such limitations are placed. Scarcity enhances the perceived value of products and opportunities, thus resulting in higher product desirability, increased quantities purchased, shorter searches, and greater satisfaction with the purchased product (Aggarwal, Jun, \& Huh, 2015, pp. 19-30; Lynn, 1991, pp. 43-57). The contrary of scarcity is availability. Scarcity can be an excellent marketing tool for businesses wanting to sell online. In fact, consumers will seek to buy online products that are not available on the traditional market.

In online environment, price is not only associated with quality, but it represents a risk. It is defined as the loss incurred when a consumer has made a simple decision to purchase a product that cannot be replaced or refunded, or a consumer has paid for the product but fail to receive it. It appears that perceptions of risk related to high cost and tangible products are still making an impact on consumers, in other words, web retailers of high cost tangible products still face challenges of narrowing the sensory gap that exists between their products and online consumers (Salisbury, R. A. Pearson, W. Pearson , \& Miller, 2001, pp. 165-176).

A recent Forrester survey found that $51 \%$ of online shoppers agreed or strongly agreed that returning products is a hassle that comes with online shopping. Although the online channel may allow targeting customers to value the ability to economize on shopping trip expenses, the fact that higher returns often accompany online purchases has implications for buying behaviour and, consequently, retailer actions. Such returns have both supply-side and demand-side implications. European online retailers experience product 
return rates of $40 \%$ or higher in product categories such as fashion (Accenture, 2012). Handling each returned item costs online retailers between $\$ 6$ and $\$ 18$ (The Economist, 2013). If retailer gets a product return, the handling costs are less than a percentage of the margin. Otherwise, there is a realization that online shoppers can lose money with every return.

\section{Research Design}

In this paper, authors used in-depth semi-structured interviewees. Using a quasi-convenience approach to informant selection, they interviewed 14 executives from 14 Italian click and brick retailers with different assortment strategies that met certain selection criteria (see Table 1). Retailer's assortment belongs to "touch and feel" because they are less suitable in ecommerce. The retailers' annual turnover ranged from $€ 5 \mathrm{~m}$ to $€ 15 \mathrm{~m}$.

Table 1

The Sample of the Research

\begin{tabular}{lll}
\hline & Occupation & Online retailer's assortment \\
\hline 1 & Assistant to the e-commerce department & Fashion \\
2 & Marketing manager & Electronic \\
3 & Head of online store & Fashion \\
4 & Head of online store & Perfumes \\
5 & Head of online store & Fashion \\
6 & Head of online communication & Shoes \\
7 & Head of sale force & Shoes \\
8 & Assistant to the e-commerce department & Fashion \\
9 & Manager customer service & Fashion \\
10 & Manager & Motorbike equipment \\
11 & Manager online marketing & Shoes \\
12 & CEO & Accessories, gifts \\
13 & CEO & Fashion, shoes, and accessories \\
14 & E-commerce project manager & Leather goods and accessories \\
\hline
\end{tabular}

The research is articulated in four different phases:

(1) Guided interviews were conducted which lasted approximately 45 minutes. All interviews were recorded and transcribed for analysis. Every interview started with a "setting-the-scene" question to obtain information on the background of the participants, the online retailer and to provide basic information on the interview's purpose.

(2) Presentation of the model. Companies understood the model and all attributes. All retailers used the model to choose which products to sell. The paper's hypothesis was: the more the products respected the following conditions, the more the selling probability increased. The best conditions were:

- Brand known

- Non sensory description (low level of touch and feel)

- Cost of return management less than $30 \%$ of margins (low cost)

- Medium or high scarcity (low availability)

- Price less than $500 €$

(3) Evaluation of the easiness of selling on line selected products compared to other. 
(4) Guided interviews explore the validity of the suggested attributes.

Grounded theory (GT) is a qualitative research approach that aims to develop theory about phenomena of interest, in which the theory needs to be rooted in observation (Glaser, 1998). Researchers transcribed each completed interview into a spreadsheet program for line-by-line analysis.

The handling costs of returned products are a very big issue for interview partners. The Number 3 describes it like this:

There is already a certain pool of costs because of the handling. The customer can return products without paying a fee. Such a return generates per-unit costs of about eight to 10 euro. If a customer purchases two units and sends one back, the seller will earn nothing on this customer. If the seller gets a product return, the handling costs are on average between $20 \%$-30\% of the price.

The statements of other informants are consistent Number 3 and emphasize the importance of product returns management and the considerable challenge returns pose for online retailers.

Number 8 said: It's difficult to sell online products without a brand, especially if the product is "touch and feel". The scarcity (high personalization or the lower price) can support the purchase.

All interviewed persons consider all of these attributes like a valid tool to select which products they can sell by Internet. The positive effects are the reduction of unsold goods, the increasing of visited pages in the web site, the reduction of costs due to returns, the increasing of income, and the rationalization of the offer.

\section{Conclusions}

The 14 companies consider the five-dimension model is valid to define the product suitability for e-commerce. Products that can be confidently purchased online and that satisfies the consumer's needs feature a known brand, low availability and low price are described essentially by non-"touch and feel" characteristics. Even when the brand is unknown, low availability and an emphasis on technical features make purchasing quite safe, as the expected value of the product closely reflects the value of the product supplied.

This study has used the Grounded Theory, in following researches, it should develop different analysis models. At moment, researchers are not able to define the weight of each attribute. Further researches can consider this issue. In this paper, authors analyzed only clicks and bricks model, other researches can evaluate web retailers. Every company belonged to the sample did not use outsourced logistics. Other companies can consider the outsourcing as a strategy to reduce the costs of returns.

\section{References}

Aaker, D. A., Batra, R., \& Myers, J. G. (1992). Advertising management (4th ed.). Lindon: Prentice Hall.

Accenture. (2012). European cross-border e-commerce: The challenge of achieving profitable growth. Retrieved on April 17.

Aggarwal, P., Jun, S. Y., \& Huh, J. H. (2015). Scarcity message effects on consumption behavior: Limited edition product considerations. Psychology \& Marketing, 32(10), 989-1001.

Cheung, C. M. K., Chan, G. W. W., \& Limayem, M. (2005). A critical review of online consumer behavior: Empirical research. Journal of Electronic Commerce in Organizations, 3, 1-19.

eMarketer. (2014). Retail sales worldwide. eMarketer Research, December.

Engel, J. F., Blackwell, R. D., \& Miniard, P. W. (1993). Consumer behaviour (7th ed.). Orlando, Florida: The Dryden Press.

Forney, J. C., Pelton, W., Caton, S. T., \& Rabolt, N. J. (1999). Country of origin and evaluative criteria: Influences on women's apparel purchase decisions. Journal of Family and Consumer Sciences, 91(4), 57-62.

Gefen, D., Karahanna, E., \& Straub, D. W. (2003). Inexperience and experience with online stores: The importance of TAM and trust. Engineering Management, 50, IEEE Transactions, 307-321.

Glaser, B. (1998). Doing grounded theory: Issues and discussions. Mill Valley: Sociology Press. 
Grapentine, T. (1995). Dimensions of an attribute. Marketing Research, 7(3), 18-27.

Ha, S., \& Stoel, L. (2009). Consumer e-shopping acceptance: Antecedents in a technology acceptance model. Journal of Business Research, 62, 565-571.

Hansen, T., Moller, J. J., \& Stubbe, S. H. (2004). Predicting online grocery buying intention: A comparison of the theory of reasoned action and the theory of planned behavior. International Journal of Information Management, 24, 539-550.

Jamal, A., \& Goode, M. (2001). Consumers' product evaluation: A study of the primary evaluative criteria in the precious jewellery market in the UK. Journal of Consumer Behaviors, 1(2), 140-155.

Keller, K. L. (2002). Branding and brand equity. In W. Bart and W. Robin (Eds), Handbook of marketing (PP. 151-178). London: Sage Publications.

Kotler, P., \& Armstrong, G. (2005). Marketing: An introduction. New Jersey: Pearson Education Incorporation.

Liefeld, J. P., Wall, M., \& Heslop, L. A. (2000). Cross cultural comparison of consumer information processing styles. In L. R. Kahle (Ed.), Cross-national consumer psychographics. New York: International Business Press.

Lin, H. (2007). Predicting consumer intentions to shop online: An empirical test of competing theories. Electronic Commerce Research and Applications, 6, 433-442.

Lynn, M. (1991). Scarcity effects on value: A quantitative review of the commodity theory literature. Psychology and Marketing, 8, 43-57.

McKechnie, S., Winklhofer, H., \& Ennew, C. (2006). Applying the technology acceptance model to the online retailing of financial services. International Journal of Retail \& Distribution Management, 34, 388-410.

Mowen, J. C. (1993). Consumer behavior (3rd ed.). New York: Macmillan Publishing Company.

Mulpuru, S. (2008). The state of retailing online 2008: Marketing report. Forrester Res.

Nielsen. (2014). E-commerce. Evolution or revolution in the fast-moving consumers goods world? The Nielsen Company, August.

Ofek, E., Katona, Z., \& Sarvary, M. (2011). Bricks and clicks: The impact of product returns on the strategies of multichannel retailers. Marketing Science, 30 (1), 42-60.

Salisbury, W. D., Pearson, R. A., Pearson, W., \& Miller, D. W. (2001). Perceived security and World Wide Web purchase intention. Industrial Management and Data Systems, 101(4), 165-176.

Soopramanien, D., Fildes, R., \& Robertson, A. (2007). Consumer decision making, e-commerce and perceived risks. Applied Economics, 39, 2159-2166.

The Economist. (2013). Return to Santa-E-commerce firms have a hard core of costly, impossible-to-please customers. Retrieved on March 1.

Tong, X. (2010). A cross-national investigation of an extended technology acceptance model in the online shopping context. International Journal of Retail \& Distribution Management, 38, 742-759.

Verhallen, T. M., \& Robben, H. S. J. (1994). Scarcity and preference: An experiment on unavailability and product evaluation. Journal of Economic Psychology, 15, 315-319.

Wu, T. W., Day, R. L., \& MacKay, D. B. (1988). Consumer benefits versus product attributes: An experimental test. Quarterly Journal of Business and Economics, 27(3), 88-113.

Zhou, L., Dai, L., \& Zhang, D. (2007). Online shopping acceptance model-A critical survey of consumer factors in online shopping. Journal of Electronic Commerce Research, 8, 41-62.

Phau, I., \& Meng Poon, S. (2000). Factors influencing the types of products and services purchased over the Internet. Internet Research, 10(2), 102-113. 